\title{
Assessment of Urban Environment Carrying Capacity Based on Catastrophe Theory
}

\author{
Peng Yue \\ School of Chemistry and Environment Protection Engineering, South West University for Nationalities, \\ Chengdu 610041, China \\ Pengyue2000@163.com
}

Keywords: Urban Environment carrying capacity; Assessment; Catastrophe theory

Abstract. Urban environment carrying capacity is limited. In this paper, catastrophe theory was applied in analyzing urban environmental system. Based on it, catastrophe progression method was presented to assess urban environment carrying capacity. By the evaluation of the single environmental element carrying capacity, the catastrophe progression model of Chengdu was built, and the catastrophe progression of this urban in different time was calculated. Comparing the standard, the results show that the urban comprehensive environmental carrying capacity of Chengdu is in the low level up and down from 2006 to 2011. The calculation steps of comprehensive environment carrying capacity assessment can be simplified by catastrophe progression method.

\section{Introduction}

Urban is a special kind of geographical environment ${ }^{[1]}$ and also is a complex ecosystem with human activities compounded with society, economy and nature, which is the result of social and economic development. In the fast growth of urban waste materials and heat which come from production and living, can not be transported to the outside in time. Then urban becomes the area concentrated by environment problems, such as atmospheric pollution, water pollution, sound pollution, heat island effect, and so on. In recent years as more and more people flock to city, more and more serious urban haze, which causes many kinds of environmental health problems and other city disease, make it necessary to review the urban environment system and its carrying capacity. Urban environment carrying capacity is the environmental strength enduring the interference from human social economic activities ${ }^{[2]}$. It can be presented by environment carrying rate.

Catastrophe theory is an effective method suitable for large system analysis ${ }^{[2]}$. Applying it in urban environmental system analysis and carrying capacity assessment is worth exploring, because it is different from AHP method and others which were widely applied in environment carrying capacity assessment.

\section{Material and Method}

Catastrophe model of urban environment system Urban environmental system is a dynamic and changeable system. The state function or potential function can be expressed by equation (1). $F$ is the state of the system.

$$
F=F(U, V) \text {. }
$$

$U$ denotes the set of state parameters $t_{i}$, and $V$ denotes the set of control parameters $u_{i}$.

When the parameters $U$ and $V$ satisfy equation (2) and (3), $F$ is the critical point of the system equilibrium state.

$$
\partial F / \partial T=0 .
$$




$$
\partial F / \partial U=0
$$

The state of urban environmental system is affected by natural environment and human social economic activity. The elements of natural environment include geology, landform, climate, hydrology, the background of atmosphere, water and soil, and etc. The elements of human social economic activity include the population change, economic development, and etc. If the two kinds of elements are regarded as two kinds of control parameters named $v$ and $u$, the cusp catastrophe model [3] of urban environment system can be built as figure1. Fig.1 shows the catastrophe manifold and bifurcation set of urban environmental system. The upper lobe of the curved surface represents the virtuous cycle of urban environmental system, in which the social economics is developed moderately, and the environmental quality is improved. The inferior lobe represents the environmental system circulation suffocate, in which the social economic development is slow, even stagnated, and the environmental quality becomes worse than before. The inferior state of urban environment system is worse than the upper state. The change of the system from upper lobe to inferior lobe means that the environmental state is suddenly deteriorated because of the sudden events in the environmental system. While the change of the system from inferior lobe to upper lobe means that the environmental state is significantly improved because of the policy measures for the urban environment system.

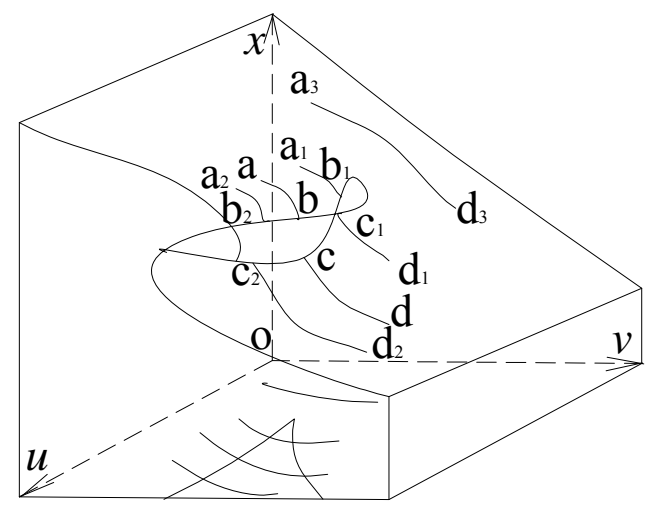

Fig.1 Cusp catastrophe model of urban environment system

The urban environmental state can be further analyzed based on the cusp catastrophe model (fig.1). In the curve named abcd, the change from point $b$ to point $c$ represents the sudden jump of the environment system state. The difference between the state of point $b$ and point $c$ can be expressed by equation (3).

$$
\Delta x=x\left(u_{b}, v_{b}\right)-x\left(u_{c}, v_{c}\right)
$$

The degree of sudden jump is different as $u$ and $v$ deteriorated in different level. In fig. 1 the sudden jump from $b_{1}$ to $c_{1}$ is expressed by equation (4), and that from $b_{2}$ to $c_{2}$ is expressed by equation (5).

$$
\begin{aligned}
& \Delta x_{1}=x\left(u_{b 1}, v_{b 1}\right)-x\left(u_{c 1}, v_{c 1}\right) . \\
& \Delta x_{2}=x\left(u_{b 2}, v_{b 2}\right)-x\left(u_{c 2}, v_{c 2}\right) \\
& \Delta x_{1}<\Delta x_{2}
\end{aligned}
$$


The formula (6) means that the latter environmental state is worse than the former. That is represented by two different length curves crossing bifurcation sets. So environment states in different time or district can be assessed by the curves.

Urban environment carrying capacity assessment of Chengdu Urban environment carrying capacity reflects the state of the urban. In order to compare the environment carrying capacities of Chengdu in different time and comprehensively reflect the urban environment problems and achievement from 2006 to 2011, catastrophe progression method ${ }^{[4]}$ was adopted for Chengdu, based on the assessment of single environmental element carrying capacity.

Catastrophe Progression Model Urban comprehensive environment carrying capacity is composed of resource carrying capacity and environment carrying capacity. Its value can be represented by environmental carrying rate. Chengdu now is a rapid expanding urban. Space resource is the first restraining element. Water resource as an important element for the inhabitants is supplied with diversion water and underground water. So land resource is in front of land resource in importance ranking. Air pollution is the most prominent environmental problem for Chengdu because of the limited accommodation space, while most of the water pollutants are contained by the rivers out of the urban. $\mathrm{NO}_{2}$ is the main air pollutant in Chengdu atmospheric environment, When $\mathrm{SO}_{2}$ as one of common air pollutants have been controlled in a certain extent. So $\mathrm{NO}_{2}$ is ahead of other air pollutants in importance ranking. In Chengdu the effect of $\mathrm{NH}_{3}-\mathrm{N}$ on water environment is becoming more and more prominent, which can be represented by the urban environmental statistics ${ }^{[3]}$, while $\mathrm{COD}$ in water environment have been controlled. So $\mathrm{NH}_{3}-\mathrm{N}$ is in front of COD in the water environmental element importance ranking. The catastrophe progression model is built as fig. 2 based on the importance ranking. The model functions and normalization equations are listed in table 1.

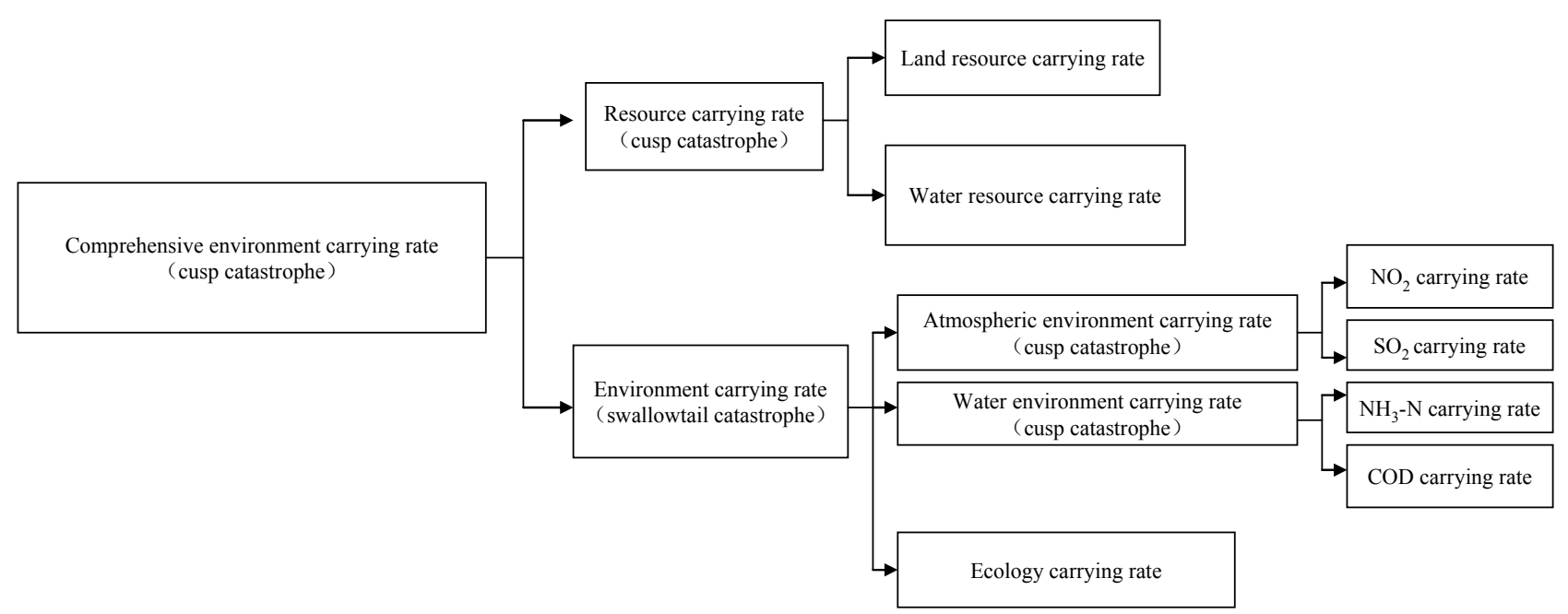

Fig. 2 Catastrophe series model of Chengdu urban comprehensive environment carrying rate

Table 1 Function and normalized equation of the catastrophe models

\begin{tabular}{cccccc}
\hline $\begin{array}{c}\text { Catastrophe } \\
\text { model }\end{array}$ & $\begin{array}{c}\text { Control } \\
\text { parameter }\end{array}$ & $\begin{array}{c}\text { State } \\
\text { parameter }\end{array}$ & Potential function & $\begin{array}{c}\text { Bifurcation } \\
\text { equation }\end{array}$ & $\begin{array}{c}\text { Normalization } \\
\text { equation }\end{array}$ \\
\hline $\begin{array}{c}\text { Cusp } \\
\text { catastrophe }\end{array}$ & $u_{1}, u_{2}$ & $x$ & $f(x)=x^{4}+u_{1} x^{2}+u_{2} x$ & $\begin{array}{c}u_{1}=-6 x^{2} \\
u_{2}=8 x^{3}\end{array}$ & $x_{u_{1}}=u_{1}^{\frac{1}{2}}$ \\
& & & $x_{u_{2}}=u_{2}{ }^{\frac{1}{3}}$ \\
$\begin{array}{c}\text { Swallowtail } \\
\text { catastrophe }\end{array}$ & $u_{1}, u_{2}, u_{3}$ & $x$ & $f(x)=x^{5}+u_{1} x^{3}+u_{2} x^{2}+u_{3} x$ & $x_{u_{1}}=u_{2}^{\frac{1}{2}}$ & $x_{u_{1}}=u_{1}^{\frac{1}{2}}$ \\
& & & & $x_{u_{3}}=u_{3}^{\frac{1}{4}}$ & $x_{u_{3}}{ }^{\frac{1}{3}}$ \\
& & & & & $u_{3}^{\frac{1}{4}}$ \\
\hline
\end{tabular}


Assessment Standard Based on the catastrophe model the final assessment standard can be deduced by the bottom data grading.

The comprehensive environment carrying situation is divided into 5 kinds of situation which are very high carrying situation, high carrying situation, middle carrying situation, relatively low carrying situation and low carrying situation. Accordingly, there are 5 kinds of carrying capacity which are week carrying capacity, low carrying capacity, middle carrying capacity, relatively high carrying capacity and high carrying capacity. The carrying rate $(0<$ carrying rate $\leq 1)$ of bottom is equidistantly divided into 5 segments: $<0.2,0.2-0.4,0.4-0.6,0.6-0.8,>0.8$. Based on the catastrophe model, 5 kinds of comprehensive environment carrying capacity rates are calculated. The results are shown in table 2.

Table 2 Evaluation grade standard of urban comprehensive environment carrying capacity

\begin{tabular}{|c|c|c|c|c|c|}
\hline \multirow[b]{2}{*}{$\begin{array}{l}\text { Comprehensive } \\
\text { environmental } \\
\text { carrying capacity }\end{array}$} & \multirow[b]{2}{*}{$\begin{array}{l}\text { Comprehensive } \\
\text { environmental } \\
\text { carrying state }\end{array}$} & \multirow[b]{2}{*}{$\begin{array}{l}\text { Environmental } \\
\text { carrying rate of } \\
\text { bottom resource }\end{array}$} & \multicolumn{3}{|c|}{ Catastrophe series method } \\
\hline & & & $\begin{array}{c}\text { Comprehensive } \\
\text { environmental } \\
\text { carrying rate }\end{array}$ & $\begin{array}{c}\text { Resource } \\
\text { carrying rate }\end{array}$ & $\begin{array}{c}\text { Environmental } \\
\text { carrying rate }\end{array}$ \\
\hline Weak & Very high & $>0.8$ & $>0.970$ & $>0.954$ & $>0.956$ \\
\hline Low & High & $0.6-0.8$ & $0.933-0.970$ & $0.809-0.954$ & $0.904-0.956$ \\
\hline Middle & Middle & $0.4-0.6$ & $0.885-0.933$ & $0.685-0.809$ & $0.835-0.904$ \\
\hline Relatively high & Relatively low & $0.2-0.4$ & $0.809-0.885$ & $0.516-0.685$ & $0.730-0.835$ \\
\hline High & Low & $<0.2$ & $<0.809$ & 0.516 & 0.730 \\
\hline
\end{tabular}

\section{Results and discussion}

The carrying rates of environmental elements resulted from the carrying capacity assessment of single environmental element make up the bottom index of Chengdu comprehensive environment carrying capacity rate. The assessment results can be gotten by normalization calculating. The assessment results are shown in table3.

Table 3 Evaluation on comprehensive urban environment carrying capacity of Chengdu

\begin{tabular}{ccccccc}
\hline Time & 2006 & 2007 & 2008 & 2009 & 2010 & 2011 \\
\hline Comprehensive environment carrying rate & 0.939 & 0.969 & 0.956 & 0.948 & 0.954 & 0.945 \\
Assessment results & Low & Low & Low & Low & Low & Low \\
\hline
\end{tabular}

In table 3 , it is shown that the urban comprehensive environment carrying capacity of Chengdu went up and down in low level from 2006 to 2011.

\section{Conclusion}

The following conclusion can be taken:

By catastrophe theory urban environment carrying capacity models can be built. By the models the calculation of urban environment carrying capacity is simplified. It becomes no necessary to weight elements like AHP method, which avoids the artificial interference. Catastrophe progression method was applied in Chengdu, the assessment results show that the urban comprehensive environment carrying capacity of Chengdu went up and down in low level from 2006 to 2011, which accords with the reality. 


\section{Acknowledgements}

This research was financially supported by the Fundamental Research Funds for the Central Universities, South West University for Nationalities (the No. 2015NYB08).

\section{References}

[1] Yixing Zhou. Urban Geography [M]. Beijing: the Commercial Press, 1995: 1 (In Chinese)

[2] Stewart, Ian. Catastrophe theory and its applications [M]. Pitman, 1978

[3] Deakin M A. Catastrophe Theory [J]. Science, 1977, 196(4296):1272-1272.

[4] Tianjun Zhang, Shuxin Rne, Shugang Li, Tiancai Zhang, Hongjie Xu. Application of the catastrophe progression method in predicting coal and gas outburst [J]. Mining Science and Technology, 2009, 19(4): 430-434 